\title{
From Mechanical Comminution to Coaxial Electrospraying: Innovation Education to the Graduate Students
}

\author{
Yong-Hui WU ${ }^{1, \text { a, }}$, Yan $\mathrm{LI}^{2}$, Wei ZHANG ${ }^{2}$, Jun ZHU², Mei-Juan LIU², Deng-Guang YU²,b, \\ ${ }^{1}$ The Department of Mechanical Engineering, Guangxi Technological College of Machinery and Electricity, \\ Nanning 530007, China \\ ${ }^{2}$ School of Materials Science \& Engineering, University of Shanghai for Science and Technology \\ Shanghai 200093, China \\ aahuiwyh@163.com, bydg017@usst.edu.cn
}

\begin{abstract}
It is a gradual development process that the creating of fine solid materials from mechanical comminution to the single-fluid electrospraying, and to the coaxial electrospraying. From these processes, a series of materials can be exploited for innovation education to the graduate students who will begin their scientific researches and puzzle to how to commence. Here, at least three kinds of materials about innovations can be drawn out for education. The first is the innovation on fabrication tools for creating small solid materials. The second is the innovation on developing novel nanomaterials with complex nanostructures. The third innovation is about building the structure-property-performance relationship for functional applications. These teaching materials should be very useful for provoking the interests of graduate students on scientific researches and promoting them to do more innovative practices.
\end{abstract}

Keywords-Innovation education; Electrospraying; Graduate student; Creativity; Nanoparticles

\section{INTRODUCTION}

During the education to postgraduate students for a master degree in high school, how to lead them to begin their scientific and innovative investigations is always a big task to their supervisors. After four years' studies about fundamental knowledge and also basic theories in their undergraduate studies, they are, on one hand, keen to carry out scientific experiments, particularly when many of them have experienced the cognitive practices in their undergraduate courses. But on the other hand, they are puzzled on two things, which may be conscious or un-conscious. One is to commence and organize their scientific experiments in a systematic manner, and the other is how to make their jobs more innovative. Both puzzles point to the key problem that the graduate students need to sublimate from a systematic grasp of their knowledge and separate experiences (accumulated in the undergraduate experiments). Thus, the start point of thinking of innovation is very important for their creativity and also their professional career because of "well begun, half done".

It is a common sense that advanced technology can act as a core for promoting discipline-crossing innovations, these innovations happen not only in itself, but also in a wide variety of related fields. All our mankind's activities with nature (both industrial and laboratory behaviors) can be divided into three steps, the selection of raw materials, the usage of advanced technology to prepare and characterize the materials, and finally the applications of resulted products in the applied fields such as energy, environment, health and hygiene, food and crops, traffic and communication, tissue engineering and pharmaceutics. The key step is to implement advanced technologies, which reflects the capability of our human kind in remaking nature. Correspondingly, these technologies should be excellent materials for teaching in higher school, particularly for the graduate students who have enough fundamental knowledge in their majors.

Today is a nano era. Numerous efforts and money have been paid to reduce solid bulk materials to micro or nano solid particles for an improved functional performances or even new functions. Here, with this topic as an objective, we conclude three kinds of materials that can be drawn out for innovation education. The first is the innovation on fabrication tools for creating small solid materials. The second is the innovation on developing novel nanomaterials with complex nanostructures. The third innovation is about building the structure-propertyperformance relationship for functional applications.

\section{INNOVATION ON FABRICATION TOOLS FOR CREATING SMALL SOLID MATERIALS}

Shown in Figure 1, a schematic diagram showing different methods for preparing fine solid materials from the bulk solid materials 1) hammering, 2) grinding, 3) high pressure homogenization, 4) spraying and 5) electrospraying. Right from the beginning of our human kind, our ancestors had known to smash bulk solid materials to small solid materials using tools such as hammer and mortar. These tools, by taking advantages of mechanical forces, can reduce the solid materials to solid powders mainly at a mm scale (maybe a small portion of them are at micron scale). To increase the production efficiency, many apparatuses such as ball mill, pneumatic pulverizer, and lapping machines have been developed for industrial applications today. A significant progress along this way is to create fine solid particles indirectly, i.e. first to dissolve the bulk solid material in a certain solvent and later 
reduce the solution to a small size [1-9]. These methods include the typical technologies such as high pressure homogenization and traditional spraying, in which mechanical forces are still exploited as the main energy to disperse. Most recently, electrospraying has developed as a brand-new method for generating fine solid particles [10-12], which is shown as 5) in Figure 1.

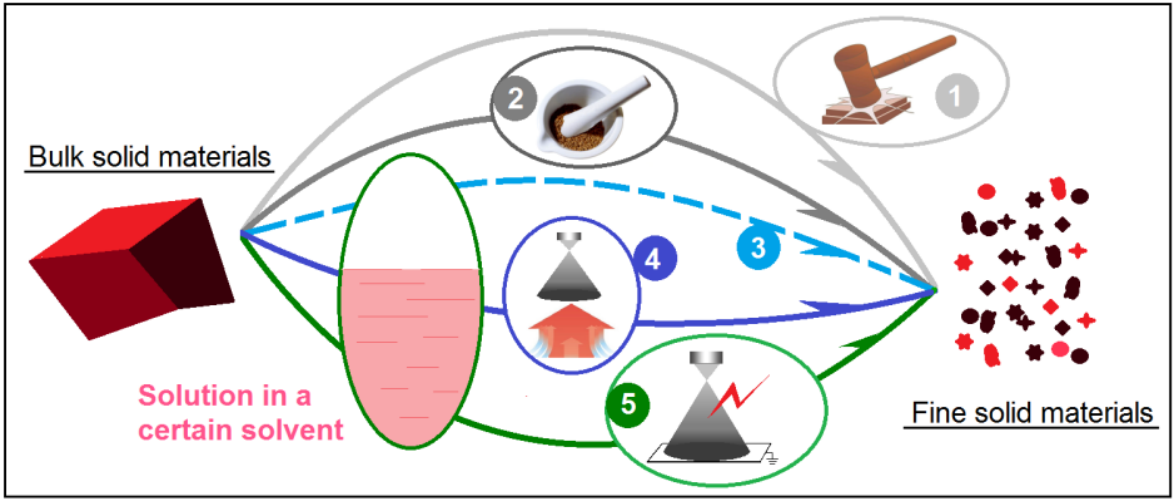

Fig. 1. A schematic diagram showing different methods for preparing fine solid materials from the bulk solid materials

Electrospraying, electrospinning and e-jetting printing are commonly termed as electrohydrodynamic atomization (EHDA) techniques, which are "top-down" processes for nano fabrications [13-16]. Different with traditional nano fabrication methods, electro-static energy is directly exploited to remove organic solvents from the working fluids for generating solid products during the EHDA processes [17-20]. These advanced material processing processes are very popular with potential applications of their products in a wide range of fields including pharmaceutics, ceramics, cosmetics energy, environmental science and food industries. Besides electrospinning, electrospraying has another counterpart, i.e. heat spraying, which has been broadly applied in many fields. Spraying takes advantage of mechanical forces to disperse the liquid and exploit heat energy to dry the liquid droplets into solid powders. These histories about the developments of fabrication tools for creating small solid materials are full of innovation stories and are very useful to show them good examples to begin their owns innovations in productions of nanoparticles.

\section{INNOVATION ON DEVELOPING NOVEL NANOMATERIALS WITH COMPLEX NANOSTRUCTURES}

As the fast developments of nanotechnologies, more and more nanoproducts have gone to commercial markets. However, almost all of them are monolithic products, i.e. the size at nanoscale is made full of usefullness for applications. In scientific researches, the nanoproducts are moving forward along three directions. One is the further reduction of size for picotechnology. The second is the ordering of nanomaterials. And the third is the preparation and application of complex nanostructures and nanosystems. A range of different complex nanoscale structures have been reported, but the core-shell and Janus structures are the most fundamental of these [21-24]. The former provides an inner-outer relationship between two compartments, and the latter a side-by-side arrangement. Both frequently appear in nature and are similarly useful starting points for creating man-made materials to provide multiple functions, or to exploit the synergetic action of two components. Other, more complex, nanoscale structures can be viewed as combinations and derivatives of these two basic architectures.

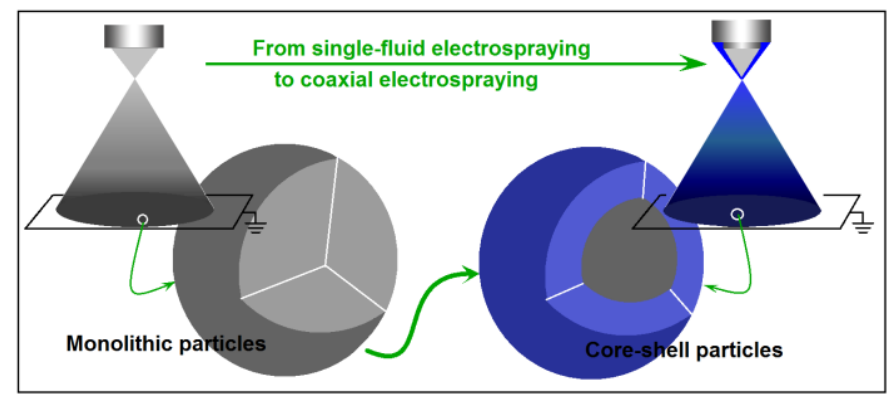

Fig. 2. Innovations about complex core-shell structures and the related developments of modern advanced nanotechnology

When traditional methods making use of mechanical forces, it is impossible that to create these complicated nanostructures in a direct "top-down" manner. In literature, most of them are generated through the "bottom-up" approaches, such as molecular self-assembly. However, coaxial electrospraying provides a possible route for creating core-shell particles in one-step and in a top-down manner. In 2002, coaxial EHDA was first reported [25]. In 2004, coaxial electrospinning was regarded as one of the most significant breakthroughs in this field [26]. In 2010, the applications of pure solvents (unelectrospinnable fluid ) as sheath working fluids to prepare fibers from concentrated polymer solutions was reported for the first time and later was utilized for a series of surface modification including nanocoating and surface functionalization. Apparently, the coaxial electrospraying is a parallel advanced technology of the traditional and modified coaxial electrospinning.

These histories about the developments of fabrication tools for creating monolithic nanoparticles to core-shell nanoparticles are highly innovative, and the coaxial electrospraying is very useful for them to be exploited for both creating novel materials and also for self-education and selfcultivation of creativity and innovation spirits. 
IV. INNOVATION IS ABOUT BUILDING THE STRUCTUREPROPERTY-PERFORMANCE RELATIONSHIP FOR FUNCTIONAL APPLICATIONS

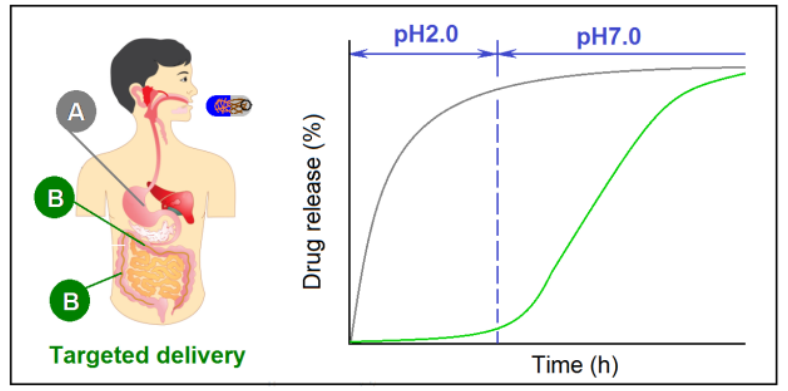

Fig. 3. Innovations about building the structure-property-performance relationship for functional applications of colon-targeted drug delivery

The core-shell nanostructures have generated numerous potential applications in both industrial products and also the experimental products in scientific laboratories. This simple inner-outer relationship has provided many possibilities for tailoring the components and compositions of the functional active ingredients and also their spatial depositions within the core-shell nanoproducts, and thus correspondingly for adjusting the functional performances of the structural nanoproducts. This paves a wide way for the graduate students to innovatively design their own functional nanomaterials. In pharmaceutics, an example is shown in Figure 3. The traditional monolithic nanoparticles will release all they contained drug at the stomach when soluble polymer is exploited as the drug carrier ("A" in Figure 3). However, when a thin layer of $\mathrm{pH}$-sensitive polymer is applied on the monolithic nanoparticles to form a core-shell structure, the drug can be sent to the colon region for local drug delivery ("B" and "C" in Figure 3) [27-29]. Certainly, there are numerous other potential applications that wait to be developed by the researchers, including the graduate students.

\section{SUMMARY}

Based on the histories about the developments from mechanical comminution to coaxial electrospraying, from traditional manners to advanced technologies for creating fine solid particles from solid bulk materials, and from the monolithic particles to the core-shell nanoparticles, a vivid innovation education can be given to the graduate students. These innovation lessons include the fabrication tools for creating small solid materials, the development of novel nanomaterials with complex nanostructures and building the structure-property-performance relationship for functional applications. These lessons should not only point the direction about innovation to the students who are puzzled about their research jobs, but also should be very useful for provoking their interests on scientific studies and promoting them to do more innovative practices.

\section{ACKNOWLEDGMENT}

The financial supports from the following projects are appreciated: the Shanghai Education Science Research Project (C17058), the National Natural Science Foundation of China (No. 51373101), the 2017 Graduate curriculum reform project in USST, the Research Project on Vocational Education and Teaching in Guang-Xi Province (GXGZJG2016A028), and the College Student Innovation Project of USST (Nos. XJ2017286, SH2017189-190-191)

\section{REFERENCES}

[1] G.Z. Yang, J.J. Li, D.G. Yu, M.F. He, J.H. Yang, G.R. Williams, Nanosized sustained-release drug depots fabricated using modified triaxial electrospraying, Acta Biomater., 53 (2017) 233-241.

[2] U.E. Illangakoon, D.G. Yu, B.S. Ahmad, N.P. Chatterton, G.R. Williams, 5-Fluorouracil loaded Eudragit fibers prepared by electrospraying, Int. J. Pharm., 495 (2015) 895-902.

[3] D.G. Yu, K. White, N. Chatterton, Y. Li, L. Li, X. Wang, Structura lipid nanoparticles self-assembled from electrospun core-shell polymeric nanocomposites, RSC Adv., 5 (2015) 9462-9466.

[4] D.G. Yu, J.J. Li, M. Zhang, G.R. Williams, High-quality Janus nanofibers prepared using three-fluid electrospraying, Chem. Commun., 53 (2017) 4542-4545.

[5] G. Chen, Y. Xu, D.G. Yu, D.F. Zhang, N.P. Chatterton, K.N. White, Structure-tunable Janus fibers fabricated using spinnerets with varying port angles, Chem. Commun., 51 (2015) 4623-3626.

[6] D.G. Yu, C. Yang, M. Jin, G.R. Williams, H. Zou, X. Wang, S.W.A. Bligh, Medicated Janus fibers fabricated using a Teflon-coated side-byside spinneret, Colloid. Surface. B, 138 (2016) 110-116.

[7] Y.H. Wu, D.G. Yu, H.P. Li, X.Y. Wu, X.Y. Li, Medicated structural PVP/PEG composites fabricated using coaxial electrospraying, ePolymers, 17 (2017) 39-44.

[8] X. Wang, X.Y. Li, Y. Li, H. Zou, D.G. Yu, J.S. Cai, Electrospun acetaminophen-loaded cellulose acetate nanofibers fabricated using an epoxy-coated spinneret, e-polymers, 15 (2015) 311-315.

[9] X. Wang, D.G. Yu, X.Y. Li, S.W.A. Bligh, G.R. Williams, Electrospun medicated shellac nanofibers for colon-targeted drug delivery, Int. J. Pharm., 490 (2015) 384-390.

[10] X.Y. Li, Z.B. Zheng, D.G. Yu, X.K. Liu, Y.L. Qu, H.L. Li, Electrosprayed sperical ethylcellulose nanoparticles for an improved sustained-release profile of anticancer drug, Cellulose, 2017, DOI: 10.1007/s10570-017-1498-0

[11] Y.H. Wu, D.G. Yu, J.J. Li, Q. Wang, H.P. Li, X.Y. Li, Medicated multiple-component polymeric nanocomposites fabricated using electrospraying, Polym. Polym. Compos. 25 (2017) 57-62.

[12] Q. Wang, H.P. Li, C. Yang, J.J. Li, D.G. Yu, Beads-on-a-string amorphous solid dispersion fabricated using a modified coaxial electrospraying, J. Control. Release, 259 (2017) e111-e112.

[13] Y.H. WU, H.P. Li, X.X. Shi, J. Wan, Y.F. Liu, D.G. Yu, Effective utilization of the electrostatic repulsion for improved alignment of electrospun nanofibers, J. Nanomater., 2016 (2016) Article ID2067383.

[14] G.Z. Yang, H.P. Li, J.H. Yang, J. Wan and D.G. Yu, Influence of working temperature on the formation of electrospun polymer nanofibers, Nanoscale Res. Lett., 12 (2017) 1-10.

[15] H.F. Wen, C. Yang, D.G. Yu, X.Y. Li, D.F. Zhang, Electrospun zein nanoribbons for treatment of lead-contained wastewater, Chem. Eng. J., 290 (2016) 263-272.

[16] Q. Wang, D.G. Yu, L.L. Zhang, X.K. Liu, M. Zhao, Electrospun hypromellose-based hydrophilic composites for rapid dissolution of poorly water-soluble drug, Carbohydr. Polym. 174 (2017) 617-625.

[17] C. Sealy, New spin on drug-loaded composite fibers, Mater. Today, 19 (2016) 374-374 
[18] D.G. Yu, X.Y. Li, X. Wang, J.H. Yang, S.W.A. Bligh, G.R. Williams, Nanofibers fabricated using triaxial electrospraying as zero order drug delivery systems, ACS Appl. Mater. Interfaces, 7 (2015) 18891-18897.

[19] D.G. Yu, H.P. Li, C. Yang, J.J. Li, Q. Wang, G.R. Williams. Doublepulsatile release core-shell fibers fabricated using modified tri-axial electrospraying, J. Control. Release, 259 (2017) e24-e25.

[20] Q. Wang, D.G. Yu, S.Y. Zhou, C. Li, M. Zhao, Fabrication of amorphous electrospun medicated-nanocomposites using a Teflon-based concentric spinneret, e-Polymer, 2017, DOI: https://doi.org/10.1515/epoly-2017-0110

[21] J.J. Li, C. Yang, H.P. Li, Q. Wang, D.G. Yu, Oral controlled release in accordance with drug adsorption biological rhythm provided by an electrospun structural amorphous solid dispersion, J. Control. Release, 259 (2017) e61-e62.

[22] Y. Xu, J.J. Li, D.G. Yu, G.R. Williams, J.H. Yang, X. Wang, Influence of the drug distribution in electrospun gliadin fibers on drug-release behavior, Eur. J. Pharm. Sci., 106 (2017) 422-430.

[23] C. Yang, D.G. Yu, D. Pan, X.K. Liu, X. Wang, S.W.A. Bligh, G.R. Williams, Electrospun $\mathrm{pH}$-sensitive core-shell polymer nanocomposites fabricated using a tri-axial processes, Acta Biomater., 35 (2016) 77-86.
[24] Y.H. Wu, D.G. Yu, X.Y. Li, A.H. Diao, U.E. Illangakoon, G.R. Williams, Fast-dissolving sweet sedative nanofiber membranes, J. Mater. Sci., 50 (2015) 3604-3613.

[25] I.G. Locertales, A. Barrero, I. Guerrero, R. Cortijo, M. Marquez, A.M. Ganan-Calvo, Micro/nano encapsulation via electrified coaxial liquid jets, Science, 295 (2002) 1695-1698.

[26] Y. Dzenis, Spinning continuous fibers for nanotechnology, Science, 304 (2004) 1917-1919.

[27] M. Jin, D.G. Yu, X. Wang, C.F.G.C. Geraldes, G.R. Williams, S.W.A. Bligh, Electrospun contrast agent-loaded fibers for colon-targeted MRI, Adv. Healthcare Mater., 5 (2016) 977-985.

[28] Y.H. WU, C. Yang, X.Y. Li, J.Y. Zhu, D.G. Yu, Medicated nanofibers fabricated using $\mathrm{NaCl}$ solutions as shell fluids in a modified coaxial electrospraying, J. Nanomater., 2016 (2016) Article ID 8970213.

[29] M. Jin, D.G. Yu, C.F.G.C. Geraldes, G.R. Williams, S.W.A. Bligh, Theranostic fibers for simultaneous imaging and drug delivery, Mol. Pharm., 13 (2016) 2457-2465. 